Research Article

\title{
Thermosetting properties of microwave-promoted heating of phenol-formaldehyde resin
}

\author{
Hisaho Hashimoto ${ }^{1}$ (1)
}

Received: 21 November 2019 / Accepted: 4 March 2020 / Published online: 7 March 2020

(c) Springer Nature Switzerland AG 2020

\begin{abstract}
Microwave-promoted heating can successfully accelerate a reaction and reduce the formation of by-products. It is also advantageous for organic synthesis because it can improve the reaction yield and opens possibilities for the development of new types of reactions. Microwave-assisted chemistry is also considered as "sustainable chemistry". In this study, the effect of microwave heating on the curing reaction of phenol-formaldehyde resin is investigated. The phenol-formaldehyde resin is a material that absorbs microwaves efficiently. It has been found that microwave heating accelerates the curing reaction of phenol-formaldehyde resin. Based on differential scanning calorimetry (DSC), it was found that the mechanisms of curing by traditional external heating and by microwave-promoted heating were different. The observed DSC profile showed an increase in the selectivity of the curing reaction by microwave heating, different from the curing reaction by traditional external heating. The observed results can be explained by the relative permittivity and dielectric loss tangent of each component of the phenol-formaldehyde resin.
\end{abstract}

\section{Graphic Abstract}

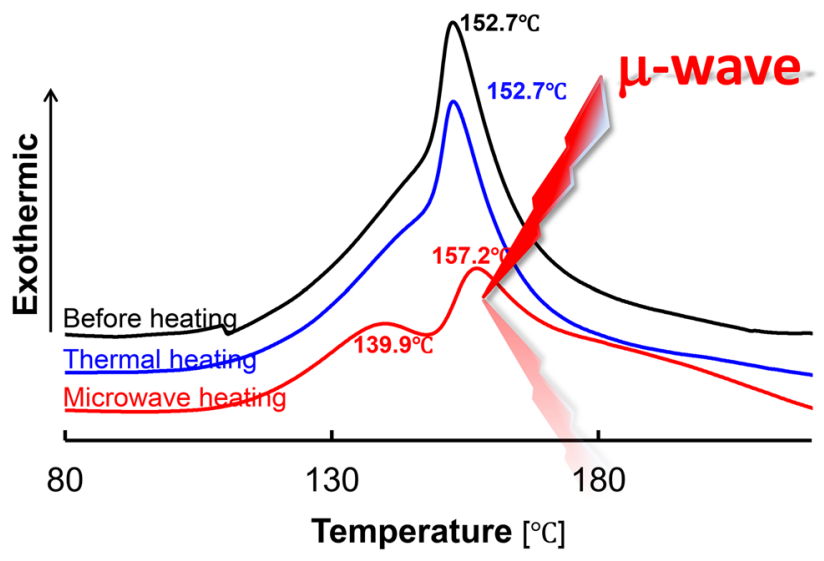

Keywords Curing reaction - Differential scanning calorimetry (DSC) - Microwave chemistry · Phenol-formaldehyde resin $\cdot$ Gel permeation chromatography (GPC)

Electronic supplementary material The online version of this article (https://doi.org/10.1007/s42452-020-2427-7) contains supplementary material, which is available to authorized users.

$\checkmark$ Hisaho Hashimoto, hisaho@tomakomai-ct.ac.jp|'Division of Applied Chemistry and Biochemistry, Department of Engineering for Innovation, National Institute of Technology (KOSEN), Tomakomai College, 443 Nishikioka, Tomakomai, Hokkaido 059-1275, Japan. 


\section{Introduction}

Chemical industry has a long history, dating back to the late 19th century, and since then, it has been supporting our modern life for over 100 years. However, the basic principle of manufacturing process, which involves the use of "heat" and "pressure" has not changed much since its conception. Therefore, chemical industry has been continuously consuming enormous amount of energy. Additionally, chemical plants have become large in size in order to control heat and pressure, and as a result vast stretches of land are required to ensure safety. One of the efforts to innovate the manufacturing process in chemical industry was the use of "microwaves". Microwaves are electromagnetic waves having a wide range of wavelength, from $1 \mathrm{~mm}$ to $1 \mathrm{~m}$, and its frequency ranges from $300 \mathrm{MHz}$ to $300 \mathrm{GHz}$, making them suitable for use in a variety of applications like communications, drying, cooking, etc. A microwave oven (frequency $2.45 \mathrm{GHz}$ ) can heat the object to the target temperature in a short time by utilizing the internal heat generated when the object undergoes vigorous molecular-level rotation and vibration induced by the microwave. The same principle is also applied for performing chemical reactions using microwaves. This technique is commonly used in fields like organic synthesis [1-7], complex synthesis [8], nanoparticle synthesis [9], solvent extraction [10], and polymer synthesis [11-15]. This process can also achieve high selectivity during synthesis and has been recognized as an excellent manufacturing tool. Microwave-enhanced heating can easily accelerate a reaction and normally produce very little by-product. It is quite advantageous for organic synthesis because it increases the reaction yield and opens up the possibilities of developing new reaction types. In addition, microwave-assisted chemistry satisfies the required criteria for being "sustainable" and "green" $[16,17]$. Horváth described that, in general, sustainable chemistry should use resources, including energy, at a rate such that they can be replaced naturally, and the generation of waste must not exceed the rate of remediation. Saving energy is one of the most important issues in all industries. Considering this factor microwave heating is one of the recommended heating methods for industrial usage.

When a dielectric substance is irradiated by microwave, an intense dipole is induced, and the dielectric starts an oscillating rotation. The electric field of microwave irradiation propagates into the dielectric substance, triggering molecular vibration, and generating heat by oscillating friction. At a constant microwave frequency and electric field intensity, the specific inductive capacity and loss angle of the dielectric substance increase, resulting in a large calorific value per unit volume. Since the specific inductive capacity and loss angles of phenolic resins are larger than those of other polymers, phenolic resins are suitable for microwave heating.

Phenolic resins have excellent material properties, such as good heat resistance, incombustibility, low fume production, electric insulation, dimensional stability, and formability $[18,19]$. Moreover, phenolic resins are inexpensive. Therefore, they have been produced and practically used since the beginning of the 20th century and have gained significance in various fields of the resin industry, such as molding materials, laminated products, plywood glues, and friction materials [20-22]. Recently, progress towards the development of electronic products has also been made using phenolic resins [23-25].

Phenolic resins are synthesized by adding formaldehyde to phenol, which proceeds via the formation of hydroxymethylphenol, also known as resol (prepolymer). Under alkaline conditions, this reaction is kinetically favored over the competing condensation reaction. Generally, the average molecular weight of the prepolymer is as low as 200-500. It is a sticky liquid that is soluble in organic solvents like alcohol and acetone. When the phenol-formaldehyde resin is heated or acidified, a condensation reaction occurs between the hydroxymethyl groups and the phenol nuclei (at the ortho- and/or para-position), forming a solid with a highly cross-linked three-dimensional network structure [23, 26-28].

In this study, we have investigated the use of microwave heating for initiating thermosetting of a phenolformaldehyde resin. The aim of our study was to reduce the thermosetting time and the electricity cost as well as to improve the uneven heating occurring due to heat transfer during the molding heating press of plywood. However, herein we found, unexpectedly, a difference in the results of differential scanning calorimetry (DSC) of the thermosetting reaction using microwave irradiation and traditional thermal heating. Microwave irradiation not only reduced the thermosetting time but also increased the selectivity of the curing reaction of the prepolymer.

\section{Experimental details}

\subsection{Materials}

Phenol (99\%), formaldehyde solution (formaldehyde content $37 \mathrm{wt} \%)$, and sodium hydroxide (97\%) were obtained from Kanto Chemical Co., Inc. and were used without further purification. 


\subsection{Prepolymer preparation}

A prepolymer of phenol-formaldehyde resin was prepared by adding formaldehyde to phenol, following the conventional method, maintaining a formaldehyde/phenol molar ratio of 2.0 and $\mathrm{NaOH} /$ phenol molar ratio of 0.2 [18]. Phenol $(30.65 \mathrm{~g}, 0.326 \mathrm{~mol})$ and $37 \%$ solution of formaldehyde $(52.85 \mathrm{~g}, 0.651 \mathrm{~mol})$ were added to a three-necked round-bottom flask equipped with a mechanical stirrer, a thermometer, and a reflux condenser. A sample $(1 \mathrm{~mL})$ corresponding to the starting time of the reaction $(0 \mathrm{~min})$, was collected from this solution, Subsequently, the reaction was initiated by adding a $48 \mathrm{wt} \%$ solution of sodium hydroxide $(5.5 \mathrm{~g}, 0.066 \mathrm{~mol})$. The reaction temperature was maintained at $90^{\circ} \mathrm{C}$, and $1 \mathrm{~mL}$ samples were collected from the reaction mixture at the reaction time points of $15,30,45,60$, and 70 min (Supplementary Material Figures S1 and S2). Subsequently, the reaction was quenched by cooling the collected samples in liquid nitrogen. The samples (before heating) were stored in a freezer $\left(-18^{\circ} \mathrm{C}\right)$, until they were subjected to either conventional heating or microwave irradiation. All the subsequent curing reactions (conventional heating and microwave irradiation) were performed using these samples.

\subsection{Microwave irradiation}

Heating by microwave irradiation was carried out using a microwave oven for organic synthesis IDX IMCR-25003 (microwave frequency: $2.45 \mathrm{GHz}$, magnetron used, Model H0911-13 manufactured by Hitachi, Ltd., power: 0-300 W), which was equipped with a temperature control system. During the course of irradiation, the temperature was maintained at $180^{\circ} \mathrm{C}$.

\subsection{GPC measurements}

GPC measurements were carried out using a chromatography system equipped with a Jasco PU-2080 Plus Intelligent HPLC pump, a column oven (Shimadzu CTO-2A, operating at $38^{\circ} \mathrm{C}$ ), a Rheodyne injector, and TOSOH TSK gel G3000HXL-G2000HXL-G1000HXL columns (linear, $7.8 \mathrm{~mm} \times 300 \mathrm{~mm}$ ). The columns were calibrated using polystyrene standards (TSK Standard PS purchased from Tosoh Co.). Resin samples were diluted to $5 \mathrm{mg} \mathrm{mL}^{-1}$ with tetrahydrofuran containing $1.6 \mathrm{mg} \mathrm{mL}^{-1}$ of formic acid. Tetrahydrofuran was used as the eluent at a flow rate of

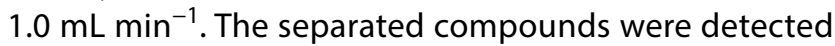
by a Shimadzu SPD-2AS UV detector at the wavelength of $254 \mathrm{~nm}$. The obtained data were analyzed using a Jasco 807-IT integrator.

\subsection{DSC experiments}

All the DSC measurements were carried out using a Shimadzu DSC-60 instrument operating with the thermal analysis software TA-60WS. The apparatus was calibrated using indium and zinc samples. Liquid resin samples (8-9 mg) were sealed in Shimadzu stainless steel pressure capsules (222-0267-92). The temperature of the samples was increased linearly under $\mathrm{N}_{2}$ atmosphere (flow rate: $50 \mathrm{~mL} \mathrm{~min}^{-1}$ ), starting at room temperature and continuing up to $250^{\circ} \mathrm{C}$ at a heating rate of $10^{\circ} \mathrm{C} \mathrm{min}^{-1}$. The calorific value was calculated from the exothermic peak area.

\section{Result and discussion}

\subsection{Preparation of prepolymer}

Figure 1 demonstrates that the molecular weight of the prepolymer of the phenol-formaldehyde resin increased with reaction time (see Supplementary Material Figure S2). Before quenching the reaction after $70 \mathrm{~min}$, the numberaverage molecular weight $\left(M_{n}\right)$ of the prepolymer of phenol-formaldehyde resin increased to a maximum of 223, and the weight-average molecular weight $\left(M_{w}\right)$ increased to a maximum of 721 . All the subsequent curing reactions were performed using the prepolymers of phenol-formaldehyde resin.

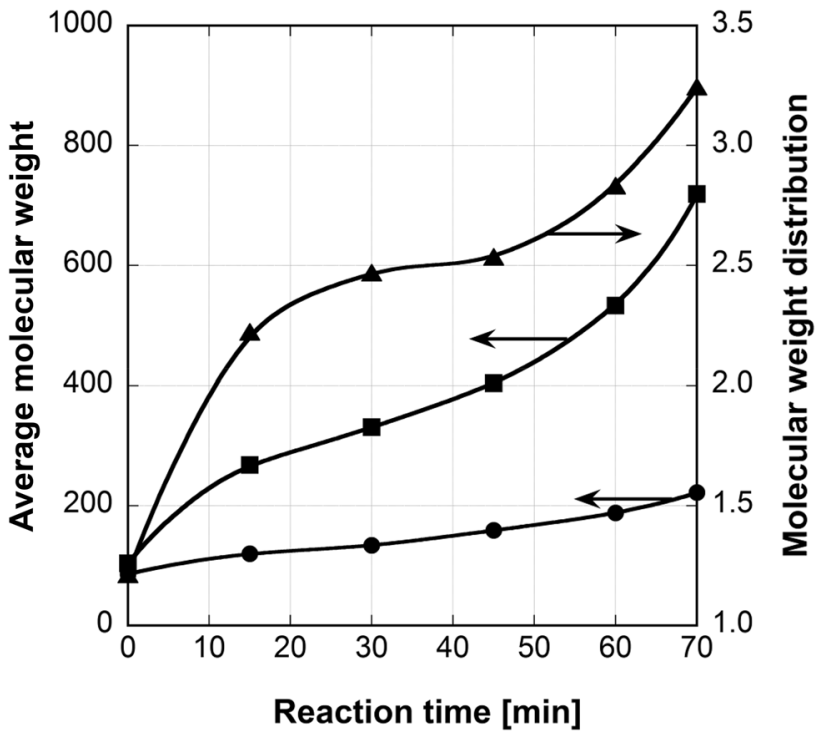

Fig. 1 Dependence of the average molecular weight and molecular weight distribution of the phenol-formaldehyde resin (prepolymer) on the reaction time $\left(\bullet\right.$; number-average molecular weight $\left(M_{n}\right), \mathbf{\square}$; weight-average molecular weight $\left(M_{w}\right), \boldsymbol{\Delta}$; molecular weight distribution $\left.\left(M_{w} / M_{n}\right)\right)$ 


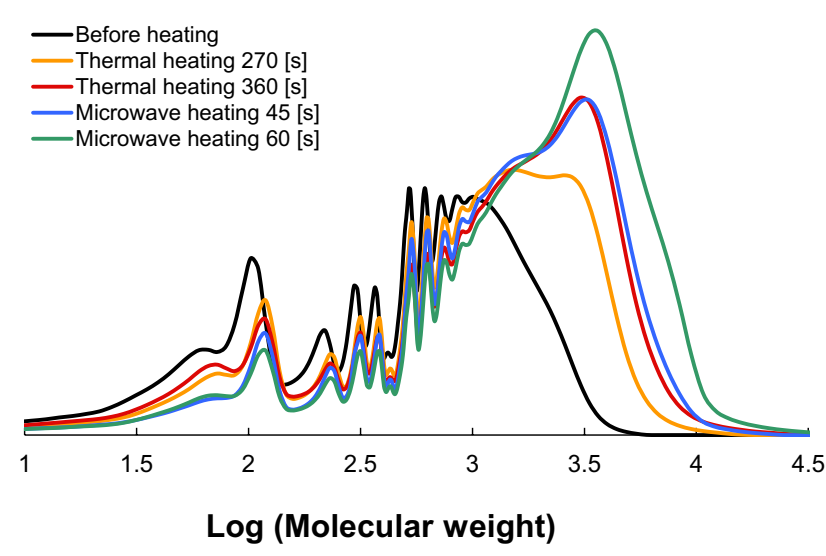

Fig. 2 GPC chromatograms of the phenol-formaldehyde resins before heating (black line) and after thermal (orange line: $270 \mathrm{~s}$; red line: $360 \mathrm{~s}$ ) and microwave heating (blue line: $45 \mathrm{~s}$; green line: $60 \mathrm{~s}$ ) at $180^{\circ} \mathrm{C}$

\subsection{Curing reaction}

The thermosetting reaction was performed on the prepared phenol-formaldehyde resin by applying standard thermal heating (in a preheated oven at $180^{\circ} \mathrm{C}$ ) as well as microwave irradiation. Figure 2 compares the GPC chromatograms of the samples heated thermally with those of the samples irradiated with microwave (see Supplementary Material Figure S3). The $M_{n}$ and $M_{w}$ values of the thermally heated sample were 310 and 1405 , respectively, after 360 s (Fig. 2, red line). In contrast, the corresponding values of the microwave-heated resin reached 397 and 1483 after irradiating for only $45 \mathrm{~s}$ (Fig. 2, blue line). This shows that microwave irradiation of the phenol-formaldehyde resin triggers the formation of a higher-molecular-weight resin. It has already been reported in a patent by Pike et al. [29] that the effective reaction of phenol-formaldehyde resin upon microwave-promoted heating proceeds more rapidly than curing by traditional heating. The results obtained in our study supported the same.

Figure 3 shows the difference in the GPC chromatograms of the thermally heated sample (after 360 s; Fig. 3, red line) and the microwave-irradiated sample (after $45 \mathrm{~s}$; Fig. 3, blue line) of comparable molecular weights. The GPC chromatogram of the phenol-formaldehyde resin before heating (Fig. 3, black line) was subtracted from both of the previous chromatograms. This demonstrates that during both the heating methods molecules with weights of 1000 or less (e.g., phenol, formaldehyde, or mono- and di-phenol nuclei, as depicted in Scheme 1) were consumed by the additional polymerization reaction, and the number of components exceeding molecular weight 1000 increased. Moreover, the consumption of unreacted phenol and

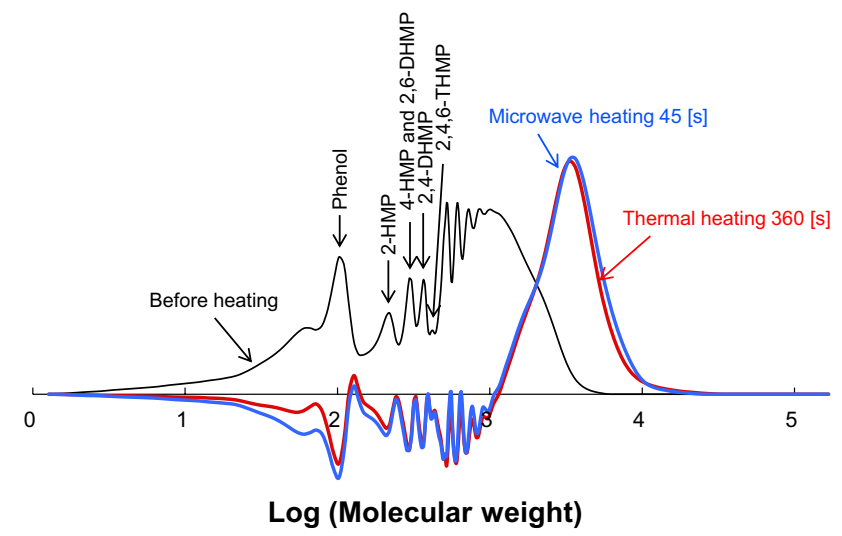

Fig. 3 Overlay of the GPC chromatogram of the phenol-formaldehyde resin before heating (black line) and the GPC difference chromatograms of the phenol-formaldehyde resin subjected to $360 \mathrm{~s}$ of thermal heating (red line) and $45 \mathrm{~s}$ of microwave heating (blue line). The difference chromatograms result from the subtraction of the GPC chromatograms measured before heating from those measured after heating the phenol-formaldehyde resin. (2-HMP: 2-(hydroxymethyl)phenol, 4-HMP: 4-(hydroxymethyl)phenol, 2,6-DHMP: 2,6-di(hydroxymethyl) phenol, 2,4-DHMP: 2,4-di(hydroxymethyl)phenol, 2,4,6-THMP: 2,4,6-tri(hydroxymethyl)phenol)

2-hydroxyphenol (2-HMP was higher for the microwaveirradiated resin than for the thermally heated resin. This suggests that the reactivities of these two chemical species were increased by microwave irradiation, which is probably due to the good microwave absorption properties of the resin (see Supplementary Material Table S1).

\subsection{DSC analysis}

The characteristic temperature range and the heat of reaction of the DSC curves provide information on the reactivity. The DSC curves of the phenol-formaldehyde resins hardened by thermal heating and microwave irradiation are shown in Fig. 4. Two exothermic peaks were observed at $150-160{ }^{\circ} \mathrm{C}$ and near $140{ }^{\circ} \mathrm{C}$. Pakkanen et al. [24, 25] ascribed the first peak to the condensation of methylol groups and phenol to form methylene bridges and the condensation of two methylol groups to form dibenzyl ether bridges (Scheme 2). The peak at $140{ }^{\circ} \mathrm{C}$ is related to further reactions of the resin, e.g. the condensation of dibenzyl ether bridges to methylene bridges via elimination of formaldehyde. During the thermally heated thermosetting reaction, both peaks decreased in intensity with increasing thermosetting time.

The Arrhenius equation provides a quantitative basis for the relationship between the activation energy $\left(E_{a}\right)$ and the rate constant $(k)$ of a chemical reaction. The equation, is written as: 


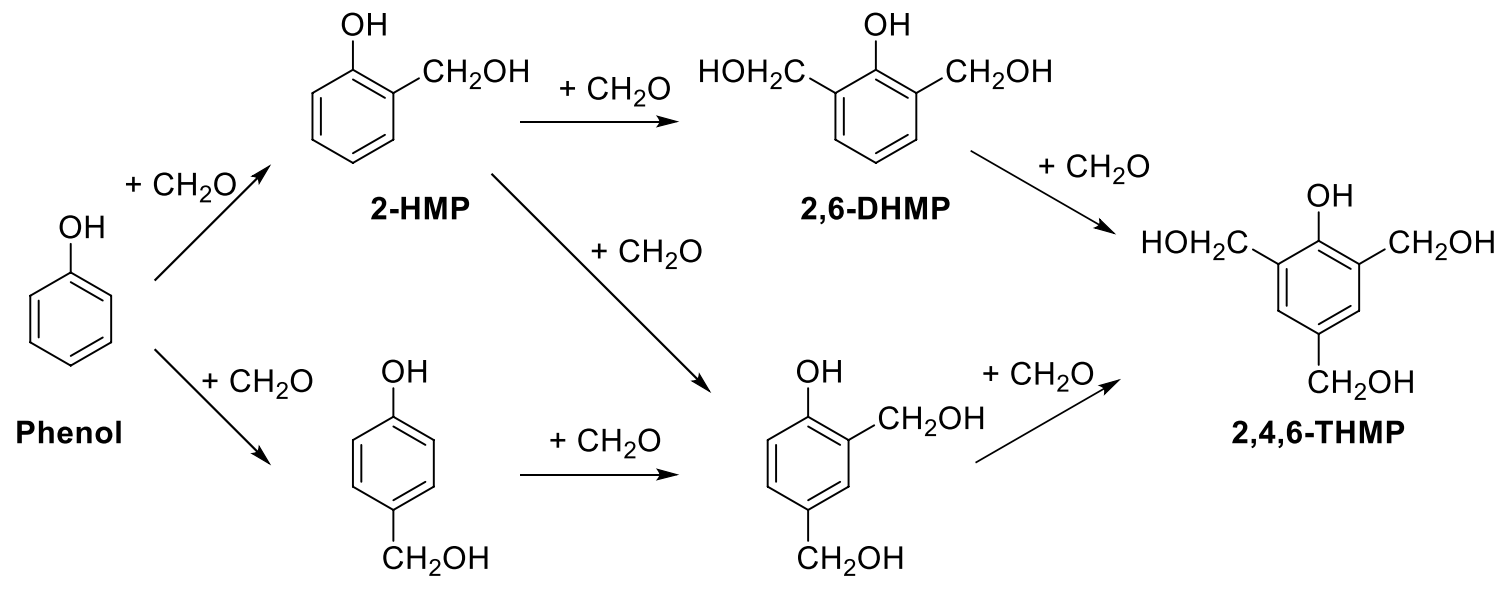

4-HMP

2,4-DHMP

Scheme 1 Synthesis scheme of the phenol-formaldehyde resin (prepolymer) by adding formaldehyde to phenol

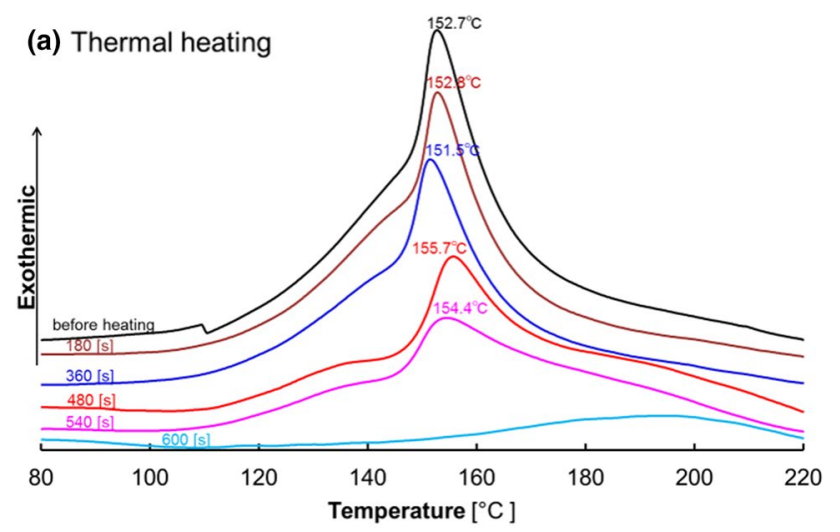

(b) Microwave heating

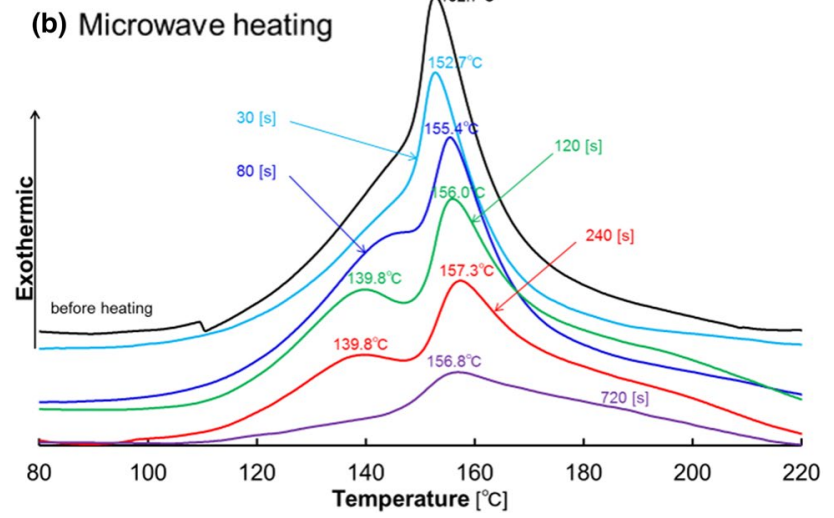

Fig. 4 DSC curves of resins before and after being subjected to a thermal heating and $\mathbf{b}$ microwave heating for different heating times
$k=A \exp \left(-\frac{E_{a}}{R T}\right)$

where $A$ is the pre-exponential factor, $R$ is the universal gas constant, and $T$ is the absolute temperature (usually in Kelvin). This is probably the case in traditional heating, where kinetically controlled reactions prevail at lower temperatures. This is because, according to the Arrhenius equation, only molecules having kinetic energy greater than the required activation energy $E_{a}$ can react. It is interpreted that the reaction proceeds beyond the activation energy barrier. However, during microwave heating, the value of the pre-exponential factor $A$ in the Arrhenius equation increases with the change in the permanent dipole. This change in permanent dipole occurs with a time delay with respect to the change in the microwave electric field. Therefore, the reaction rate constant increases and the heat generated increases the temperature. Thus, thermodynamically controlled reactions are also accelerated [30]. As a result, it may be possible to reverse the selectivity of the reaction, which is determined by the magnitude of the activation energy. This explains why microwave reactions are favored over traditional heating.

Figure 4 demonstrates that all the three curing reaction processes shown in Scheme 2 proceeded successfully. However, the peak at $140{ }^{\circ} \mathrm{C}$ decreased only during the curing reaction under microwave irradiation. Thus, the two peaks in the DSC curves of Fig. 4 show a remarkable separation with increasing microwave irradiation time. This suggests that under microwave irradiation, the two reactions at $140{ }^{\circ} \mathrm{C}$ cannot proceed as easily as the reactions at higher temperatures $\left(150-160{ }^{\circ} \mathrm{C}\right)$, which occur immediately (Scheme 2). 
Scheme 2 Reaction scheme of the three curing reactions: a formation of the methylene group, $\mathbf{b}$ formation of the dimethylene ether group, and c the condensation reaction (a) Fromation of methylene group

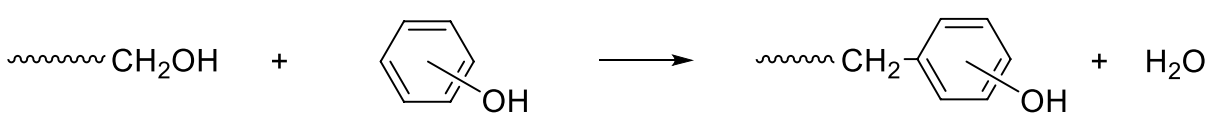

(b) Formation of dimethylene ether group

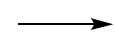

$\sim m \sim \mathrm{CH}_{2}-\mathrm{O}-\mathrm{CH}_{2} \sim m n+\mathrm{H}_{2} \mathrm{O}$

(c) Condensation reaction

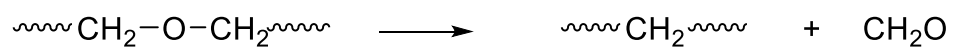

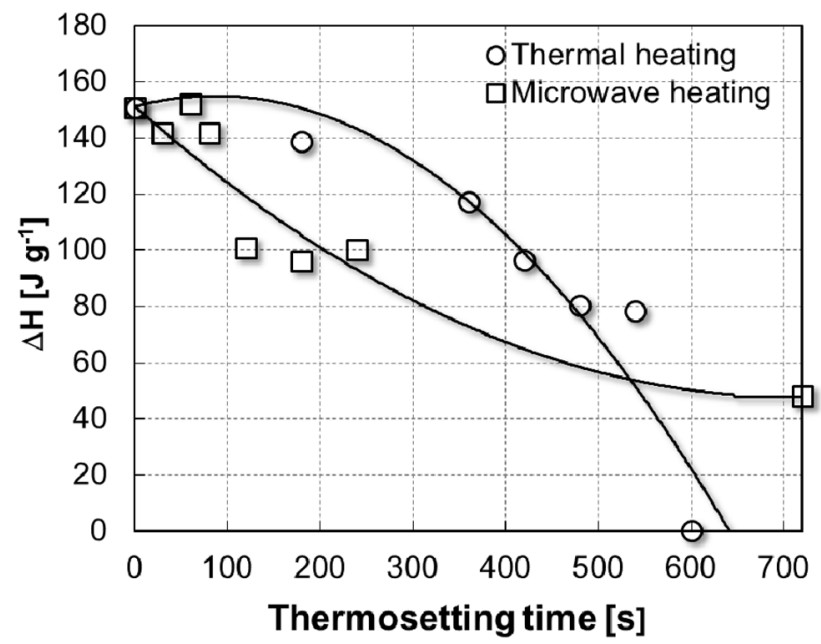

Fig. 5 DSC analysis of the dependence of the calorific value on the thermosetting time ( $\bigcirc$; thermal heating, $\square$; microwave irradiation)

Calorific values were calculated from the DSC peaks, and the dependence of the calorific values on the microwave irradiation time is shown in Fig. 5. This demonstrates that the calorific value decreases under microwave irradiation, which further indicates that the curing reaction is initiated as soon as the microwave irradiation starts. In contrast, the decrease in the calorific value of thermal heating is delayed by approximately $200 \mathrm{~s}$, indicating slower initiation of the curing reaction. Moreover, after continuing thermal heating for $600 \mathrm{~s}$, the calorific value decreased to zero. In contrast, microwave heating caused a decrease in the calorific value to only $50 \mathrm{~J} \mathrm{~g}^{-1}$, which corresponds to one-third of its initial value of $150 \mathrm{~J} \mathrm{~g}^{-1}$. According to the literature $[24,25,31,32]$, the exothermic DSC peak of the curing reaction at $\sim 140^{\circ} \mathrm{C}$ is related to the reaction of phenolic rings and hydroxymethyl groups, and the exothermic peak at $150-160{ }^{\circ} \mathrm{C}$ is attributed to the reaction between two hydroxymethyl groups, leading to the formation of a dimethylene ether group, in addition to the removal of formaldehyde from the dimethylene ether groups via formation of methylene bridges. Therefore, microwave heating increases the selectivity and reaction rate of the reactions at higher temperatures $\left(150-160^{\circ} \mathrm{C}\right)$ compared to the reactions occurring at lower temperatures (approximately $140{ }^{\circ} \mathrm{C}$ ). The elucidation of this relationship is currently underway in our laboratories.

Dielectric loss, i.e. power $(P)$ consumed as heat by the dielectric per unit volume is

$P=\omega \cdot \varepsilon_{r} \cdot C_{0} \cdot V^{2} \cdot \tan \delta$

In this equation, the relative permittivity $\varepsilon_{r}$ and the dielectric loss angle $\tan \delta$ are values specific to the substance. The product, $\varepsilon_{r} \cdot \tan \delta$, is called the dielectric loss factor. This indicates the degree of microwave power absorbed by the dielectric.

In other words, the amount of heat generated in the dielectric is proportional to the frequency $(\omega)$, the electrostatic capacitance in vacuum $\left(C_{0}\right)$, the square of the voltage $\left(V^{2}\right)$, and the loss factor. If the frequency and voltage are the same, the higher the loss factor, greater is the heat generated. Therefore, the loss factor can be considered a factor that represents the ease with which a substance can generate heat due to high-frequency dielectric heating. The value of loss factor is determined by the type of dielectric, temperature, and frequency, and it also varies depending on the type of dielectric. Since the amount of heat generated is proportional to the loss factor, when a high-frequency voltage is applied to an object composed of several different dielectrics, instead of a single dielectric, the amount of heat generated by each dielectric becomes non-uniform. In other words, among the reactions that occur in the curing reaction of phenol-formaldehyde resin, it can be considered that a specific reaction is preferentially (selectively) caused by microwave irradiation.

Of course, this also applies to cases where phenol-formaldehyde resin is used for wood panel manufacturing. Because the loss factor of phenol-formaldehyde resin is higher than cellulose [33], the main component of wood, heating of the wood panel during curing of phenol-formaldehyde resin is avoided. 


\section{Conclusions}

Microwave irradiation polarizes phenol-formaldehyde resins, which changes their thermal motion and heat generation, and thus, causes a difference in the reactivity of the resin during the curing reaction. Microwave-promoted heating not only accelerates the curing reaction more than traditional heating, but also selectively promotes the curing reaction that occurs at higher temperatures. The condensation of methylol groups and phenol to form methylene bridges and the condensation of two methylol groups to form dibenzyl ether bridges dominate the reaction that occurs at lower temperatures, which is the condensation of dibenzyl ether bridges to methylene bridges with the elimination of formaldehyde.

Using this technique, control over the curing reaction of phenol-formaldehyde resins was attained at the molecular level, making this technique potentially useful for fabricating phenolic resins with high performance and advanced features.

\section{Compliance with ethical standards}

Conflict of interest The authors declare that they have no conflicts of interest.

\section{References}

1. Adam D (2003) Out of the kitchen. Nature 421:571-572. https:// doi.org/10.1038/421571a

2. Hoz A, Loupy A (eds) (2013) Microwaves in organic synthesis, 3rd edn. Wiley-VCH, Weinheim. https://doi.org/10.1002/97835 27651313

3. Kappe CO (2004) controlled microwave heating in modern organic synthesis. Angew Chem Int Ed 43(46):6250-6284. https ://doi.org/10.1002/anie.200400655

4. Kappe CO, Pieber B, Dallinger D (2013) Microwave effects in organic synthesis: myth or reality? Angew Chem Int Ed 52(4):1088-1094. https://doi.org/10.1002/anie.201204103

5. Rosana MR, Tao Y, Stiegman AE, Dudley GB (2012) On the rational design of microwave-actuated organic reactions. Chem Sci 3(4):1240-1244. https://doi.org/10.1039/c2sc01003h

6. Dudley GB, Stiegman AE, Rosana MR (2013) Correspondence on microwave effects in organic synthesis. Angew Chem Int Ed 52(31):7918-7923. https://doi.org/10.1002/anie.201301539

7. Li AY, Kaushik M, Li C-J, Moores A (2016) Microwave-assisted synthesis of magnetic carboxymethyl cellulose-embedded Ag$\mathrm{Fe}_{3} \mathrm{O}_{4}$ nanocatalysts for selective carbonyl hydrogenation. ACS Sustain Chem. Eng 4(3):965-973. https://doi.org/10.1021/acssu schemeng.5b01048

8. Rao KJ, Vaidhyanathan B, Ganguli M, Ramakrishnan PA (1999) Synthesis of inorganic solids using microwaves. Chem Materials 11(4):882-895. https://doi.org/10.1021/cm9803859

9. Zheng A, Zhao K, Jiang L, Zhao Z, Sun J, Huang Z, Wei G, He F, Li H (2016) Bridging the gap between pyrolysis and fermentation: improving anhydrosugar production from fast pyrolysis of agriculture and forest residues by microwave-assisted organosolv pretreatment. ACS Sustain Chem. Eng 4(9):5033-5040. https://doi.org/10.1021/acssuschem eng.6b01416

10. Ikeda S, Mori T, Ikeda Y, Takao K (2016) Microwave-assisted solvent extraction of Inert platinum group metals from $\mathrm{HNO}_{3}(\mathrm{aq})$ to betainium-based thermomorphic ionic liquid. ACS Sustain Chem. Eng. 4(5):2459-2463. https://doi.org/10.1021/acssu schemeng.6b00186

11. Ebner C, Bodner T, Stelzer F, Wiesbrock F (2011) One decade of microwave-assisted polymerizations: quo vadis? Macromol Rapid Commun 32(3):254-288. https://doi.org/10.1002/ marc.201000539

12. Ramier J, Renard E, Grande D (2012) Microwave-assisted ringopening polymerization of d, I-lactide: a probe for the nonexistence of nonthermal microwave effects. Macromol Chem Phys 213(7):784-788. https://doi.org/10.1002/macp.201200008

13. Wiesbrock F, Hoogenboom R, Schubert US (2004) Microwaveassisted polymer synthesis: state-of-the-art and future perspectives. Macromol Rapid Commun 25(20):1739-1764. https://doi. org/10.1002/marc.200400313

14. Schubert US, Hoogenboom $R$ (2007) Special issue: microwaves and polymers. Macromol Rapid Commun 28(4):357-513

15. Mgbemena C, Li D, Lin M, Liddel P, Katnam K, Kumar V, Nezhad $H$ (2018) Accelerated microwave curing of fiber-reinforced thermoset polymer composites for structural applications: a review of scientific challenges. Compos Part A: Appl Sci Manuf 115:88-103. https://doi.org/10.1016/j.compositesa.2018.09.012

16. Horváth IT (2018) Introduction: sustainable chemistry. Chem Rev 118(2):69-371. https://doi.org/10.1021/acs.chemrev.7b00721

17. Grewal AS, Kumar K, Redhu S, Bhardwaj S (2013) Microwave assisted synthesis: a green chemistry approach. Int Res J Pharm Appl Sci (IRJPAS) 3(5):278-285

18. Lee YK, Kim DJ, Kim HJ, Hwang TS, Rafailovich M, Sokolov J (2003) Activation energy and curing behavior of resol- and novolac-type phenolic resins by differential scanning calorimetry and thermogravimetric analysis. J Appl Polym Sci 89(10):2589-2596. https://doi.org/10.1002/app.12340

19. Qiao W, Li S, Guo G, Han S, Ren S, Ma Y (2015) Synthesis and characterization of phenol-formaldehyde resin using enzymatic hydrolysis lignin. J Ind Eng Chem 21:1417-1422. https://doi. org/10.1016/j.jiec.2014.06.016

20. Gabilondo N, López M, Ramos JA, Echeverria JM, Mondragon I (2007) Curing kinetics of amine and sodium hydroxide catalyzed phenol-formaldehyde resins. J Therm Anal Calorim 90(1):229236. https://doi.org/10.1007/s10973-006-7747-3

21. Shudo Y, Izumi A, Hagita K, Nakao T, Shibayama M (2017) Structure-mechanical property relationships in crosslinked phenolic resin investigated by molecular dynamics simulation. Polymer 116:506-514. https://doi.org/10.1016/j.polymer.2017.02.037

22. Zhang $R$, Jin $X$, Wen $X$, Chen $Q$, Qin D (2018) Alumina nanoparticle modified phenol-formaldehyde resin as a wood adhesive. Int J Adhes Adhes 81:79-82. https://doi.org/10.1016/j.ijadh adh.2017.11.013

23. Gardziella A, Pilato LA, Knop A (2000) phenolic resins-chemistry, applications, standardization, safety and ecology. Springer, Berlin

24. Holopainen T, Alvila L, Rainio J, Pakkanen TT (1997) Phenolformaldehyde resol resins studied by ${ }^{13} \mathrm{C}-\mathrm{NMR}$ spectroscopy, gel permeation chromatography, and differential scanning calorimetry. J Appl Polym Sci 66(6):1183-1193. https://doi. org/10.1002/(SICI)1097-4628(19971107)66:6\%3c1183:AIDAPP18\%3e3.0.CO;2-2

25. Luukko P, Alvila L, Holopainen T, Rainio J, Pakkanen TT (2001) Effect of alkalinity on the structure of phenol-formaldehyde 
resol resins. J Appl Polym Sci 82(1):258-262. https://doi. org/10.1002/app.1846

26. Fink JK (2013) Chapter 4 - Phenol/Formaldehyde resins, Reactive Polymers Fundamentals and Applications, 2nd edn. William Andrew Publishing, Oxford, pp 155-177

27. Pizzi A, Stephanou A (1993) On the chemistry, behavior, and cure acceleration of phenol-formaldehyde resins under very alkaline conditions. J Appl Polym Sci 49(12):2157-2170. https ://doi.org/10.1002/app.1993.070491212

28. Granado L, Tavernier R, Foyer G, David G, Caillol S (2018) Comparative curing kinetics study of high char yield formaldehydeand terephthalaldehyde-phenolic thermosets. Thermochim Acta 667:42-49. https://doi.org/10.1016/j.tca.2018.06.013

29. Pike RL, Barnes D (1977) Microwave curing of alkaline phenolic resins in wood-resin components. Patent, US 4018642A

30. Adnadjevic B, Jovanovic J (2012) Chem Inform abstract: the effect of microwave heating on the isothermal kinetics of chemicals reaction and physicochemical processes. Chem Inform 43(18):391-422. https://doi.org/10.1002/chin.201218263
31. Kenny JM, Pisaniello G, Farina F, Puzziello S (1995) Calorimetric analysis of the polymerization reaction of a phenolic resin. Thermochim Acta 269(270):201-211. https://doi.org/10.1016/00406031(95)02356-9

32. King PW, Mitchell RH, Westwood AR (1974) Structural analysis of phenolic resole resins. J Appl Polym Sci 18(4):1117-1130. https ://doi.org/10.1002/app.1974.070180412

33. Torgovnikov GI (1993) Dielectric properties of wood-based materials. In: Timell TE (ed) Dielectric properties of wood and wood-based materials. Springer series in wood science. Springer, Berlin, pp 157-158

Publisher's Note Springer Nature remains neutral with regard to jurisdictional claims in published maps and institutional affiliations. 